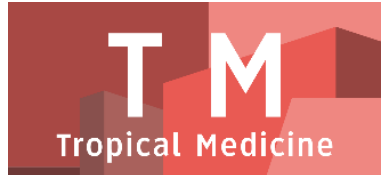

PAPER - OPEN ACCESS

\title{
Identifikasi Senyawa Kimia Aktif Antioksidan Dari Ekstrak Etil Asetat Buah Andaliman (Zanthoxylum acanthopodium DC)
}

\author{
Author : Wiwi Winarti \\ DOI $\quad: 10.32734 /$ tm.v1i3.283 \\ Electronic ISSN : 2623-0542 \\ Print ISSN : 2623-0550
}

Volume 1 Issue 3 - 2018 TALENTA Conference Series: Tropical Medicine (TM)

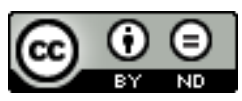

This work is licensed under a Creative Commons Attribution-NoDerivatives 4.0 International License.

Published under licence by TALENTA Publisher, Universitas Sumatera Utara
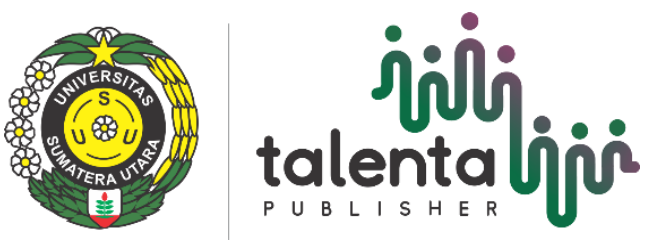


\title{
Identifikasi Senyawa Kimia Aktif Antioksidan Dari Ekstrak Etil Asetat Buah Andaliman (Zanthoxylum acanthopodium DC)
}

\author{
Wiwi Winarti ${ }^{\mathrm{a}^{*}}$, Partomuan Simanjuntak ${ }^{\mathrm{b}}$, Muhammad Fahmi Syahidin $^{\mathrm{c}}$ \\ ${ }^{a c}$ Fakultas Farmasi Universitas Pancasila Jakarta 12640 \\ ${ }^{b}$ Puslit Bioteknologi, LIPI Cibinong 16911 \\ winartiwiwi25@gmail.com
}

\begin{abstract}
Abstrak
Buah andaliman, (Zanthoxylum acanthopodium DC), banyak dikonsumsi oleh masyarakat sebagai bumbu makanan dan obat tradisional seperti obat sakit perut, tonikum, dan anti mikroba. Penelitian ini bertujuan untuk mengidentifikasi senyawa yang berkhasiat sebagai antioksidan dari ekstrak buah andaliman. Ekstraksi dilakukan secara maserasi kinetik menggunakan pelarut $n$ heksan, dan etil asetat. Ekstrak kental yang diperoleh kemudian diuji aktivitas antioksidan dengan metode peredaman radikal bebas menggunakan DPPH. Sebagai kontrol positif digunakan vitamin C. Selanjutnya dilakukan pemurnian dengan kromatografi kolom sampai diperoleh isolat EA.X.6.1 yang mempunyai aktivitas antioksidan tertinggi. Hasil uji aktivitas antioksidan dengan metode peredaman radikal bebas DPPH (1,1-difenil-2-pikrilhidrazil) menunjukkan bahwa ekstrak etil asetat buah andaliman mempunyai aktivitas antioksidan dengan nilai IC50 sebesar 66,91 bpj, dan isolat EA.X.6.1 yang memiliki aktivitas antioksidan tertinggi dengan nilai IC50 sebesar 135,58 bpj. Berdasarkan hasil analisis dengan spektrofotometri UV-Vis, spektrofotometri Fourier Transform Infra Red (FT- IR) dan Kromatografi Gas-Spektrometri Massa (KG-SM) diduga senyawa aktif antioksidan yang terdapat dalam ekstrak etil asetat buah andaliman adalah 2-metoksi-4-vinilfenol.
\end{abstract}

Kata kunci: Buah Andaliman, Zhanthoxylum acanthopodiam DC, antioksida

\begin{abstract}
Andaliman fruits (Zanthoxylum acanthopodium DC) have been consumed by many people as a food seasoning and traditional medicine for stomachache, tonic, anti microbials. This study aimed to identify antioxidant active compounds in extract of andaliman fruits. Ectraction was done by maceration kinetics methods were carried out using $n$-hexane and ethyl acetate as solvents, then tested their extracts antioxidant activity by free radical scavenging method using DPPH. Vitamin C was used as a positive control. Afterwards, purification by column chromatography and indicated that the ethyl acetate phase extract had the highest antioxidant activity with IC50 values of $66,91 \mathrm{ppm}$ and isolate EA.X.6.1 had the highest antioxidant activity with IC50 values of $135,58 \mathrm{ppm}$. According to the UV-Vis, Fourier Transform Infra Red (FT-IR), and Gas Chromatography-Mass Spectrometry (GC-MS) spectra analysis, the antioxidant active compounding ethyl acetate extract of andaliman fruits is predicted as 2-metoxy-4-vinylphenol.
\end{abstract}

Keywords: Andaliman fruits, Zanthoxylum acanthopodium DC, antioxidant 


\section{Pendahuluan}

Radikal bebas merupakan senyawa kimia yang mempunyai satu atau lebih elektron bebas yang tidak berpasangan. Radikal bebas ini dapat terbentuk dari dalam maupun luar tubuh. Di dalam tubuh, radikal bebas merupakan produk samping proses metabolisme. Sedangkan dari luar tubuh, radikal bebas dapat terserap masuk melalui pernapasan atau kulit. Radikal bebas ini bersifat sangat reaktif sehingga mudah menyerang sel-sel lain di dalam tubuh. Serangan radikal bebas dapat menyebabkan penyakit degeneratif seperti penyakit jantung, rematik dan beberapa penyakit pada otak, ginjal, paru-paru, sistem pencernaan, dan kekebalan tubuh. Secara alami tubuh menghasilkan suatu senyawa kimia untuk menangkal radikal bebas yang disebut antioksidan. Antioksidan merupakan senyawa kimia yang dapat mencegah terjadinya proses oksidasi dengan memberikan elektron pada molekul radikal bebas sehingga menghambat reaksi berantai dari radikal bebas di dalam tubuh. Senyawa antioksidan alam yang memiliki aktivitas paling tinggi diantaranya adalah vitamin C, vitamin E, beta karoten, dan senyawa golongan polifenol seperti flavonoid (flavon, flavan, flavonol, dan senyawa fenolik). Flavonoid merupakan senyawa golongan polifenol yang memiliki lebih dari satu gugus hidroksil (-OH) dengan beberapa fungsi yang diketahui,yaitu penangkapan radikal bebas, penghambatan enzim oksidasi dan hidrolisis, serta pencegahan reaksi peradangan atau inflamasi. [1].

Salah satunya tanaman yang memiliki banyak khasiat adalah tanaman andaliman. Tanaman andaliman dalam ilmu tumbuhan dikenal dengan nama Zanthoxylum acanthopodium DC. Di Indonesia, tanaman ini hanya dijumpai pada daerah tapanuli, Sumatera Utara , tanaman ini tumbuh liar di pegunungan dengan ketinggian $1400 \mathrm{~m}$ di atas permukaan laut pada temperatur $15-18^{\circ} \mathrm{C}$. Tanaman ini tersebar antara lain di India Utara, Nepal, Pakistan Timur, Myanmar, Thailand, dan China [2].

Penelitian antioksidan terhadap buah andaliman masih terbatas. Aktivitas antioksidan ekstrak etanol buah andaliman dalam beberapa sistem pangan menyatakan bahwa aktivitas antioksidan ekstrak etanol buah andaliman pada konsentrasi 200 ppm adalah 61,81\% (3), Krisanty (4). melaporkan bahwa setelah dilakukan elusidasi struktur kimia senyawa hasil isolasi dari ekstrak $n$-butanol melalui penelusuran spektroskopi, senyawa ZAB-1 adalah 17((23E,26E) -23- etiliden -29- hidroksi -29- (2hidroksipropoksi) -25- metildek -26- en -20- il) -13,15-dimetil-gona1,3,5(10)-trien-3-ol dan senyawa ZAB-2 adalah senyawa kolest-5-en-3 $\beta$-il $\beta$-D-glukopiranosida. Katzer (5), dalam penelitiannya menyatakan bahwa fraksi non volatil dari genus Zanthoxylum diidentifikasi mengandung senyawa flavonoid, terpen, alkaloid, quartenary isoquinoline alkaloid, aporphyrine alkaloid, dan beberapa jenis ligan. Ligan ini sendiri adalah senyawa yang diduga berperan sebagai antioksidan.

Tujuan penelitian ini adalah untuk mengisolasi, mengidentifikasi atau mengkarakterisasi senyawa aktif antioksidan yang terdapat dalam ekstrak non polar dan semi polar buah andaliman (Zanthoxylum acanthopodium DC) menggunakan metode peredaman radikal bebas dengan menggunakan DPPH (1,1-Difenil-2-Pikrilhidrazil)

Pada penelitian ini dilakukan isolasi dan identifikasi senyawa kimia antioksidan yang diduga terdapat pada ekstrak $n$ - heksan dan etil asetat buah andaliman, selanjutnya masing-masing ekstrak dilakukan pengujian aktivitas antioksidan Ekstrak yang diduga memiliki aktivitas antioksidan tertinggi kemudian dilakukan fraksinasi dengan kromatografi kolom, fraksi yang paling aktif akan dimurnikan sehingga diperoleh isolat. Isolat ini akan diidentifikasi struktur molekulnya dengan menggunakan Spektrofotometer terhadap UV- Vis, Gas Chromatography-Mass Spectrometry (GC-MS) dan Spektrofotometer Fourier Transform Infrared (FT-IR).

\section{Bahan dan Metode}

Bahan yang digunakan dalam penelitian ini adalah buah andaliman (Zanthoxylum acanthopodium DC) yang diperoleh dari Kecamatan Berastagi, Kabupaten Karo, Sumatera Utara. Bahan yang diperoleh telah diderminasi di Herbarium Bogoriense Bidang Botani, Pusat Penelitian LIPI (Lembaga Ilmu Pengetahuan Indonesia), Cibinong, 16911, Bogor.

Penelitian di awali dengan pembuatan ekstrak $n$-heksan dan etilasetat buah andaliman secara ekstraksi bertingkat dengan metode maserasi kinetik. Selanjutnya setiap fase dipekatkatkan dengan rotavapor sampai diperoleh ekstrak kental $n$-heksan dan etilasetat. Ekstrak kental $n$-heksan dan etiasetat dilakukan uji aktivitas antioksidan dengan metode peredaman radikal bebas Difenil-2-Pikrilhidrazil (DPPH).

Ekstrak yang memiliki aktivitas antioksidan tertinggi dilakukan Fraksinasi dengan kromatografi kolom I. Fraksi- 
fraksi hasil kromatografi kolom I disederhanakan dengan melihat pola kromatogram KLT yang sama digabungkan menjadi satu fraksi, selanjutnya pengujian aktivitas antioksidan terhadap fraksi gabungan hasil kromatografi kolom I. Fraksi gabungan yang mempunyai aktivitas antioksidan paling tinggi difraksinasi dengan kromatografi kolom II untuk menyederhanakan senyawa-senyawa yang terkandung didalamnya. Fraksi-fraksi hasil kromatografi kolom II disederhanakan dengan melihat pola kromatogram KLT fraksi yang sama digabungkan menjadi satu fraksi. Fraksi gabungan hasil kromatografi kolom kedua diuji aktivitas antioksidannya dan dipilih salah satu fraksi yang paling aktif.

Fraksi hasil kromatografi dimurnikan dengan KLT preparatif dengan fase gerak yang sesuai. Isolat hasil KLT preparatif diuji aktivitas antioksidannya dengan metode peredaman radikal bebas DPPH dan dipilih isolat yang paling aktif. Isolat diidentifikasi struktur kimianya dengan kromatografi gas-spektrometri massa, gugus kromofor dengan spektrofotometri UV-Vis dan gugus-gugus fungsionalnya diidentifikasi menggunakan spektrofotometri FTIR.

\section{Hasil Dan Pembahasan}

Hasil ekstraksi dari 1.010 gram serbuk buah andaliman (Zanthoxylum acanthopodium DC.) menggunakan pelarut $n$-heksan etil asetat secara maserasi kinetik, menggunakan 19,8 liter $n$-heksan dan 18,6 liter etil asetat (maserasi dilakukan 6 kali).Hasil ekstraksi diperoleh ekstrak n- heksan(Rendemen2,31\%, DER 43,25) dan ekstrak etilasetat (Rendemen1,962\%, DER 50,98). Hasil disajikan pada tabel 1.

Tabel 1. Hasil rendemen ekstrak buah andaliman

\begin{tabular}{|c|c|c|c|c|}
\hline No. & Sampel & Berat (gram) & Rendemen (\%) & DER \\
\hline 1 & Ekstrak $n$-heksan & 23,35 & 2,31 & 43,25 \\
\hline 2 & Ekstrak etil asetat & 19,81 & 1,96 & 50,98 \\
\hline
\end{tabular}

Uji aktivitas antioksidan ekstrak buah andaliman dengan metode peredaman radikal bebas DPPH bertujuan untuk memilih salah satu diantara ekstrak $n$-heksan dan etil asetat dari buah andaliman yang mempunyai aktivitas antioksidan paling tinggi. Hasil uji pendahuluan aktivitas antioksidan dilakukan pada konsentrasi sampel sebesar 150 ppm karena pada konsentrasi tersebut didapatkan nilai hambatan aktivitas radikal bebas lebih dari $70,00 \%$. Hasil uji aktivitas antioksidan ekstrak buah andaliman disajikan pada tabel 2.

Tabel 2.. Hasil uji aktivitas antioksidan ekstrak buah andaliman

\begin{tabular}{|c|c|c|c|}
\hline \multirow{2}{*}{\multicolumn{2}{|c|}{ Pengukuran }} & \multicolumn{2}{|c|}{ Ekstrak } \\
\hline & & n-heksan & Etil Asetat \\
\hline $\mathrm{C}$ & & 150 & 150 \\
\hline $\mathrm{Ab}$ & & 0,805 & 0,805 \\
\hline \multirow[t]{2}{*}{ As } & As1 & 0,732 & 0,246 \\
\hline & As2 & 0,734 & 0,236 \\
\hline \multicolumn{2}{|c|}{ As rata-rata } & 0,733 & 0,241 \\
\hline \multicolumn{2}{|c|}{ Peredaman radikal bebas } & 8,94 & 70,06 \\
\hline
\end{tabular}

Berdasarkan data di atas ekstrak etilasetat mempunyai aktivitas antioksidan paling tinggi $(70,06 \%)$ dengan nilai iC50 sebesar 66,91 bpj, kemudian dilanjutkan dengan tahapan pemisahan menggunakan kromatografi kolom.

Hasil kromatografikolom I didapat sebelas (11) fraksi gabungan, selanjutnya diuji aktivitas antioksidannya untuk mengetahui fraksi gabungan mana yang memiliki nilai persen hambat terbesar. 
Hasil uji aktivitas antioksidan fraksi gabungan hasil kromatografi kolom I diperoleh fraksi EA.X sebagai fraksi yang mempunyai aktivitas antioksidan paling tinggi bila dibandingkan dengan fraksi lainnya. Aktivitas peredaman radikal bebas fraksi EA.X sebesar 87,61 \% dan Ic50 48,36 bpj, kemudian dilanjutkan dengan tahapan pemisahan menggunakan kromatografi kolom II.

Hasil uji antioksidan menunjukkan bahwa fraksi EA.X.6 yang mempunyai aktivitas antioksidan paling tinggi sebesar $67,53 \%$.

Hasil analisis KLT menunjukkan fraksi EA.X.6 masih mempunyai beberapa bercak sehingga perlu dilakukan pemurnian dengan KLT preparatif dengan menggunakan fase gerak kloroform - metanol (20:1). Pola kromatogram fraksi EA.X.6 dari hasil KLT-preparatif menunjukkan adanya 2 pita, yaitu pita 1 dan pita 2 yang diduga mengandung senyawa X. Hasil kromatogram disajikan pada gambar.1.

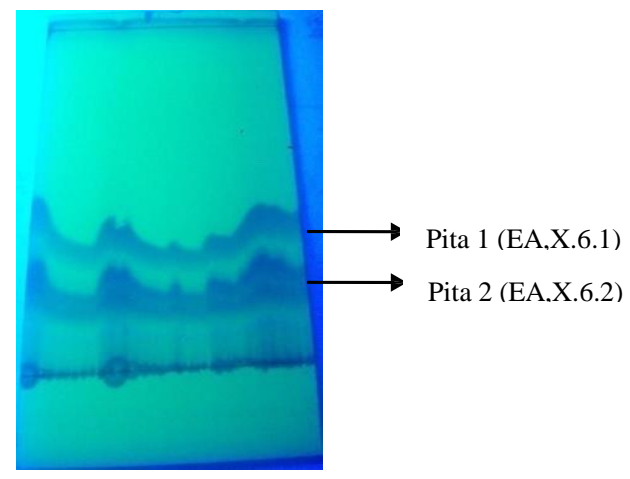

Gambar1. KromatogramKLT-preparatiffraksiEA.X.6

Dari ke 2 pita hasil isolasi dengan KLT preparatif dikerok lalu serbuk silika gel yang diperoleh dikumpulkan dalam vial lalu dilarutkan dengan menggunakan pelarut metanol p.a. Didapatkan isolat EA.X.6.1 dan isolat EA.X.6.2. Kemudian dilakukan pengujian aktivitas antioksidan.

Hasil uji aktivitas antioksidan diperoleh isolat EA.X.6.1 sebagai isolat yang mempunyai aktivitas antioksidan paling tinggi sebesar $59.84 \%$.

Dari hasil penentuan peredaman aktivitas radikal bebas didapatkan bahwa isolat EA.X.6.1 lebih tinggi dibandingkan dengan isolat EA.X.6.2, yaitu didapatkan aktivitas peredaman radikal bebas isolat EA.X.6.1 sebesar 59,84\% dengan nilai iC50 sebesar 135,58 bpj.

Berdasarkan hasil interpretasi dari tiga instrumen yang digunakan, dimana pada spektra UV-Vis didapat hasil senyawa mempunyai ikatan rangkap, lalu pada spektra FTIR didapat munculnya cincin aromatik, gugus alkena, eter dan hidroksil, sedangkan pada kromatogram KG-SM didapat beberapa peak (puncak) dimana satu diantaranya memiliki nilai kemiripanyaitu 97\% menurut database Willey09th.L. Perkiraan dari hasil analisis yang diperoleh dapat disimpulkan bahwa senyawa kimia isolat EA.X.6.I diduga adalah senyawa 2-metoksi-4-vinilfenol dengan struktur kimia pada gambar 2.



Gambar 2.: 2-metoksi-4-vinilfenol 


\section{Kesimpulan}

Hasil identifikasi spektrofotometri UV-Vis, FTIR, dan KG-SM diduga merupakan senyawa 2-metoksi-4vinilfenol.

\section{Ucapan Terima Kasih}

Penulis mengucapkan termakasih kepada Puslit Bioteknologi, LIPI Cibinong Bogor yang telah menfasilitasi penelitian ini.

\section{Daftar Pustaka}

[1] Patel S, Parmar K. 2011. Evaluation of Antioxidant Activity, Phenol and Flavonoid Content of (Momordica charanthia Linn. Fruit. Shah Collage of Pharmaceutical Education \& Research.1(2).

[2] Hasairin A. 1994. Etnobotani Rempah dalam Makanan Adat Masyarakat Batak Angkola dan Madailing. Bogor: Tesis Program Sarjana IPB.

[3] Suryanto E, Sastrohamidjojo H, Raharjo S. Tranggono. 2004. Antiradical activity of andaliman (Zanthoxylum acanthopodium DC.) fruit extract. Indonesian Food and Nutrition Progress.II (1): 15-19.

[4] Kristanty RE. 2012. Isolasi dan Elusidasi Struktur Senyawa Antioksidan dan Penghambat Xantin Oksidase dari Buah Andaliman. Depok: Program S2 Ilmu Kefarmasian FMIPA Universitas Indonesia.

[5] Katzer S. Sichuan Pepper . 2004. (Zanthoxylum piperatum/simulans/bungeanum/rhetsa/achanthopodium and others). 2004.

[6] Molyneux P. 2004 The use of the stable free radical diphenylpycryl-hydrazyl (DPPH) for estimating antioxidant activity. Songklanakarin J. Sci. Technol.; 26(2): 211-9, 214-215

[7] Tensiska C, Wijaya H, Nuri Andarwulan. 2003. Aktivitas antioksidan ekstrak buah andaliman (Zanthoxylum acanthopodium DC) dalam beberapa sistem pangan dan kestabilan aktivitasnya terhadap kondisi suhu dan $\mathrm{pH}$. jurnal teknologi dan industri pangan ; XIV (1): 29-39. 